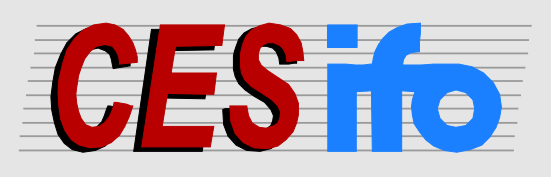

\title{
Working
}

Papers

www.cesifo.org/wp

\section{Modelling the Fiscal Reaction Functions of the GIPS Based on State-Varying Thresholds}

\author{
Gabriella Legrenzi \\ Costas Milas
}

\section{CESIFO WORKING PAPER NO. 4385 \\ CATEGORY 1: PUBLIC FinANCE \\ SEPTEMBER 2013}

Presented at CESifo Area Conference on Public Sector Economics, April 2013

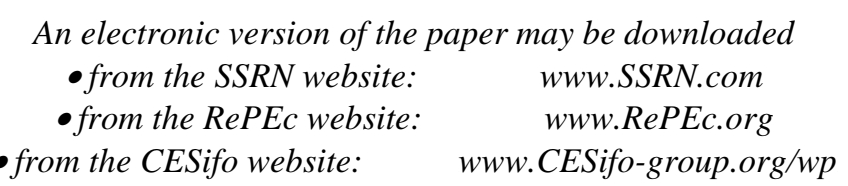




\title{
Modelling the Fiscal Reaction Functions of the GIPS Based on State-Varying Thresholds
}

\begin{abstract}
We extend previous literature on fiscal policy sustainability by introducing non-linear fiscal reaction functions with endogenously estimated state-varying thresholds to capture the behaviour of fiscal policy authorities during "good" and "bad" times. These thresholds vary with the level of debt, the economic cycle and an index of financial pressure.
\end{abstract}

JEL-Code: C200, H300, H500.

Keywords: debt sustainability, fiscal reaction function, state-varying threshold.

Gabriella Legrenzi

Keele University

Keele Management School

Darwin Building DW 1.68

UK - Staffordshire ST5 5BG

g.d.legrenzi@keele.ac.uk
Costas Milas

Liverpool University

Management School

Chatham Street

UK - Liverpool L69 7ZH

costas.milas@liverpool.ac.uk 


\section{Introduction}

We estimate non-linear fiscal reaction functions (FRF) for four Eurozone countries (Greece, Ireland, Portugal and Spain; the GIPS), by introducing adjustment thresholds conditional not only on the size of debt but also on the state of the economy and a measure of financial pressure, thereby providing a more accurate description of the behaviour of fiscal policy authorities. Common features of the GIPS include bail-outs from the ECB, the IMF and the European Commission. This justifies the recent concerns and offers a useful ground for sustainability testing. ${ }^{1}$

\section{The GIPS’ Fiscal Reaction Function}

The model-based FRF approach to fiscal sustainability testing requires the estimation of:

$$
\mathrm{PRIMSURPL}_{t}=a_{0}+\rho \mathrm{DEBT} \mathrm{T}_{t}+\varepsilon_{t}
$$

where PRIMSURPL $L_{t}$ is the ratio of primary surplus to GDP and $D E B T_{t}$ is the ratio of debt to GDP. A sufficient condition for sustainability is $\rho>0$, implying that governments undertake corrective actions to counteract changes in debt (see, e.g. Bohn, 1998).

A linear FRF such as (1), nevertheless, implicitly assumes that corrective action is invariant with the size of debt, whilst theoretical political economy models suggest a non-linear adjustment, due to the difficulties in reaching the necessary consensus to fiscal consolidation (see, e.g. Bertola and Drazen, 1993). Most recent literature considers some non-linearities in the FRF; Mendoza and Ostry (2008) estimate a cubic FRF for a panel of 56 countries, showing that higher debt countries (in terms of the mean/median of the panel) fail the sustainability test. A similar result is obtained by Theofilakou and Stournaras (2012), for a panel of EU countries exceeding the 60\% Maastricht debt criterion. Such literature is nevertheless based on an exogenously created ad-hoc state-invariant threshold, which is arguably unrealistic given the current Eurozone crisis.

We relax the assumption of a continuous and state-invariant fiscal adjustment by estimating the

\footnotetext{
${ }^{1}$ Greece, which was bailed-out twice (for $€ 110$ bn in 2010 and then again for $€ 109 b n$ in 2011) negotiated, in February 2012, a new €130bn rescue package involving a voluntary haircut of some 53.5\% on the face value of its bonds held by the private sector. Eurozone ministers agreed (in November 2012) to cut Greece's debt by a further $€ 40 \mathrm{bn}$. Ireland was bailed-out for €85bn in November 2010. Portugal was bailed-out for €78bn in May 2011. Spain was granted, in July 2012, financial assistance from the European Stability Mechanism for up to €100bn.
} 
following non-linear FRF:

$$
\begin{aligned}
& \triangle \text { PRIMSURPL }_{t}=\beta_{0}+\left(\beta_{11} C V_{t-1}+\beta_{12} \text { cycle }_{t}\right) \theta_{t-1}^{S}+\left(\beta_{21} C V_{t-1}+\beta_{22} \text { cycle }_{t}\right)\left(1-\theta_{t-1}^{S}\right)+ \\
& +\beta_{3} \Delta D E B T_{t-1}+\beta_{4} \text { finpressure }_{t}+u_{t}
\end{aligned}
$$

where $C V_{t-1}$ are the residuals from the long-run relationship between $P R I M S U R P L_{t}$ and $D E B T_{t}$, cycle $_{t}$ is a measure of the economic cycle, $u_{t}$ is a stochastic error term, $u_{t} \sim$ i.i.d. $\left(0, \sigma_{u}^{2}\right)$ and

$$
\theta_{t-1}^{s}=1-\left[1+\exp \left(-\gamma^{s}\left(s_{t-1}-\tau^{s}\right) / \sigma_{s_{t-1}}\right)\right]^{-1}
$$

is the logistic transition function (see e.g. van Dijk et al, 2002). According to (2)-(3), fiscal policy exhibits regime-switching behavior which depends on whether $s_{t-1}$ (the transition variable) is below or above an endogenously estimated threshold, $\tau^{s}$ with regime weights $\theta_{t-1}^{S}$ and $\left(1-\theta_{t-1}^{s}\right)$, respectively ${ }^{2}$. The parameter $\gamma^{s}>0$ determines the smoothness of the transition regimes. We make $\gamma^{s}$ dimension-free by dividing it by the standard deviation of $s_{t-1}$ (Granger and Teräsvirta, 1993). We consider $D E B T_{t-1}$ and $c y c l e_{t-1}$ as possible transition variables. The use of $D E B T_{t-1}$ allows for regime-switching corrective fiscal action based on the history of debt, that is, (past) debt-to-GDP ratio values above or below an estimated threshold. Cycle $e_{t}$ is proxied by real GDP growth and by the output gap (i.e. output relative to a Hodrick-Prescott (1997) trend using, for annual data, the conventional smoothing (lambda) parameter of 100). The use of cycle allows for regime-switching corrective fiscal action based on economic performance measured by high versus low GDP growth, and by deviations of output from its trend. Further, we introduce a state-varying threshold of the form:

$\tau_{t}^{D E B T}=\tau_{0}^{D E B T}+\tau_{1}^{D E B T}$ finpressure $_{t}$,

where $\tau_{0}^{D E B T}$ is a fixed threshold and $\tau_{1}^{D E B T}>0(<0)$ implies that during periods of financial pressure, policymakers raise (lower) the debt ceiling above which corrective action is taken; finpressure is a composite measure of financial turmoil/crisis and draws heavily on Reinhart and Rogoff (2009) $)^{3}$.

\footnotetext{
${ }^{2}$ In preliminary analysis, we allowed for the intercept term, $\triangle D E B T_{t-1}$ and the finpressure variable (discussed below) to vary between regimes but failed to find such evidence.

${ }^{3}$ The index takes into account banking, currency, stock market, debt, and inflation incidences in the world. It pools together world's 20 largest economies with country specific weights given by their relative GDP share of the total
} 


\section{Empirical estimation of the GIPS' non-linear FRF: the main results}

We use, for each country, the longest available annual time series data from the annual macroeconomic database (AMECO) of the European Commission and the International Monetary Fund (IMF). The debt-to-GDP series is taken from the historical public debt database compiled by the IMF (and linked to the IMF's World Economic Outlook). The series corresponds to the gross general government debt scaled by nominal GDP (for further details see Abbas et al, 2010). The primary surplus to GDP series is taken from AMECO and corresponds to the general government net lending/borrowing (ublgi) scaled by nominal GDP. Figure 1 plots the fiscal data whereas Figure 2 plots real GDP growth (available from the IMF) and our financial pressure variable. Preliminary analysis using Augmented Dickey Fuller (ADF) unit root tests suggests that PRIMSURPL and DEBT are both I(1) for all countries, consequently we estimate (1) using Johansen's (1995) methodology. PRIMSURPL and DEBT are cointegrated with a small positive $\rho$, pointing to the sustainability of the GIPS fiscal policies. Consistent with the government budget identity, we also note that rather than (1), a more common "backward-looking” approach of the form PRIMSURPL $L_{t}=a_{0}+\rho D E B T_{t-1}+\varepsilon_{t}$ is often met in the literature (see e.g. Afonso and Jalles, 2012; Bohn, 2007). Using this approach makes little difference to our estimates. ${ }^{4}$ Least Squares estimates of the short-run models are reported in Tables 1-4 (rather than assuming strict exogeneity of cycle $_{t}$ and finpressure $_{t}$, we have also employed 2-Stage Least Squares using an intercept, $C V_{t-1}, \triangle D E B T_{t-1}$, and three lags of both cycle $_{t}$, and finpressure $t_{t}$ as instruments; this made no qualitative difference to the results reported here). All GIPS adjust budgetary disequilibria only in the higher debt regime, and the debt threshold for adjustment is estimated at 69\% for Greece, 49\% for Ireland, 47\% for Portugal and 43\% for Spain.

With respect to the state-varying component, for all GIPS the $\tau_{1}^{D E B T}$ estimates are negative and

GDP (based on Purchasing Power Parity). As alternative measures of financial market pressure, we used the (i) spread between the 10-year yield on the GIPS and the 10-year yield on German bonds, and (ii) a 2(and 3)-year moving standard deviation of the spread but failed to find any significant effect.

${ }^{4}$ Using (1), we estimate $\rho=0.040$ (standard error $=0.013$ ) for Greece, $\rho=0.104$ (standard error $=0.033$ ) for Ireland, $\rho=0.030$ (standard error $=0.010$ ) for Portugal and $\rho=0.020$ (standard error $=0.009$ ) for Spain. Using PRIMSURPL $L_{t}=a_{0}+\rho D E B T_{t-1}+\varepsilon_{t}$, we estimate $\rho=0.041$ (standard error=0.015) for Greece, $\rho=0.100$ (standard error $=0.029$ ) for Ireland, $\rho=0.027$ (standard error $=0.012$ ) for Portugal and $\rho=0.019$ (standard error $=0.004$ ) for Spain. 
statistically significant, suggesting that, during a period of financial pressure, all GIPS lower the debt threshold, possibly in response to financial market concerns.

We also find a statistically significant growth threshold close to $3 \%$ for all GIPS, whilst the output gap resulted statistically insignificant (results on request), signalling that GIPS fiscal authorities might be more concerned with output growth rather than output relative to potential (see e.g. Fatas and Mihov (2008)). For all GIPS, both the cycle impact and fiscal adjustment become stronger when the economy is slowing down (the cycle impact is insignificant for Greece). This suggests some degree of fiscal imprudence from the GIPS's end; instead of prioritising fiscally responsible actions during good times, their corrective action is stronger when growth weakens. For all countries, model (2)-(4) with the state-varying threshold provides the best fit (in terms of a lower regression standard error). The bottom line of each Table reports the Chow forecast test for structural stability due to the recent economic/financial crisis (we test for a break when the crisis erupted in 2007). The test highlights the superiority of the non-linear over the linear models; the former do not fail structural stability but the latter do.

\section{Conclusions}

We have introduced non-linear FRF with state-varying thresholds to describe the behaviour of the GIPS fiscal policy authorities. Whilst linear models would support the sustainability of the GIPS fiscal policy, our approach documents some relevant shortcomings, justifying current market concerns. Greece fiscal position within this model stands out as its threshold is higher than the $60 \%$ reference value of the Maastricht Treaty, its fiscal adjustment is much slower and the primary surplus does not respond to the economic cycle. Further, under pressure from financial markets, all countries lower the debt ceiling above which corrective action is taken. Hence, pressure by financial markets appears to be more effective than the formal excessive deficit procedure (EDP) in making member states correct fiscal imbalances.

\section{Acknowledgements}

We would like to thank Athanasios Tagkalakis (Bank of Greece), Alfons Weichenrieder, the participants at the 2013 CESifo Area Conference on Public Sector Economics, the $69^{\text {th }}$ IIPF Annual Congress in Taormina and the 12th Munich Economic Summit for useful feedback and suggestions. Financial assistance from CESifo and BMW Stiftung Herbert Quandt is gratefully 
acknowledged.

\section{References}

Abbas, S.M. Ali, N. Belhocine, A. El-Ganainy and M. Horton (2010). A Historical Public Debt Database, IMF Working Paper WP/10/245, Washington, DC.

Afonso, A., Jalles, J. T., 2012. Revisiting fiscal sustainability. Panel cointegration and structural breaks in OECD countries. European Central Bank Working Paper series No. 1465.

Bertola, G., Drazen A., 1993. Trigger points and budget cuts: explaining the effects of fiscal austerity. American Economic Review 83, 11-26.

Bohn, H., 1998. The behavior of US public debt and deficits. Quarterly Journal of Economics 113, 949-963.

Bohn, H., 2007. Are Stationarity and Cointegration Restrictions Really Necessary for the Intertemporal Budget Constraint?. Journal of Monetary Economics 54, 1837-1847.

Fatas, A., Mihov, I., 2008. The Euro and Fiscal Policy. National Bureau of Economic Research Working Paper series No. 14722.

Granger, C.W.J., Teräsvirta, T., 1993. Modelling Nonlinear Economic Relationships. Oxford: Oxford University Press.

Hodrick, R, Prescott, E.C., 1997. Postwar U.S. Business Cycles: An Empirical Investigation. Journal of Money, Credit, and Banking 29, 1-16.

Johansen, S., 1995. Likelihood-Based Inference in Cointegrated Vector Autoregressive Models. Oxford University Press, Oxford.

Mendoza, E.G., Ostry, J.D., 2008. International Evidence on Fiscal Solvency: Is Fiscal Policy "Responsible"?. Journal of Monetary Economics 55, 1081-1093.

Reinhart, C.M., Rogoff, K.S., 2009. This Time is Different. Eight Centuries of Financial Folly. Princeton University Press, Princeton and Oxford.

Theofilakou, N., Stournaras, Y., 2012. Government Solvency and Financial Markets: Dynamic Panel Estimates for the European Monetary Union. Economics Letters 115, 130-133.

van Dijk, D., Teräsvirta, T., Franses, P.H. 2002. Smooth Transition Autoregressive Models - a Survey of Recent Developments. Econometric Reviews 21, 1-47. 
Table 1: GREECE-OLS estimates of alternative models for $\triangle P R I M S U R P L_{t}, 1960-2012$

\begin{tabular}{|c|c|c|c|c|}
\hline & (i) Linear model & $\begin{array}{l}\text { (ii) Logistic model (2)- } \\
\text { (3) in text with } \\
s_{t-1}=D E B T_{t-1}\end{array}$ & $\begin{array}{l}\text { (iii) Logistic model (2)-(4) } \\
\text { in text with } s_{t-1}=D E B T_{t-1} \\
\text { and state-varying threshold }\end{array}$ & $\begin{array}{l}\text { (iv) Logistic model } \\
\text { (2)-(3) in text with } \\
s_{t-1}=\text { cycle }_{t-1}\end{array}$ \\
\hline Intercept & $-1.052(-1.13)$ & $-1.102(-1.16)$ & $-1.095(-1.15)$ & $-1.517(-1.56)$ \\
\hline$C V_{t-1}$ & $-0.270(-2.68)$ & & & \\
\hline finpressure $_{t}$ & $-0.063(-0.07)$ & $0.071(0.08)$ & $0.064(0.07)$ & $0.395(0.64)$ \\
\hline$\Delta D E B T_{t-1}$ & $0.177(1.40)$ & $0.154(1.41)$ & 0.149 (1.44) & $0.161(1.43)$ \\
\hline cycle $_{t}$ & 0.090 (1.093) & & & \\
\hline & & $\boldsymbol{D E B T}_{t-1}<\tau^{D E B T}$ & $\boldsymbol{D E B T}_{t-1}<\tau_{t}^{D E B T}$ & cycle $_{t-1}<\tau^{\text {cycle }}$ \\
\hline$C V_{t-1}$ & & $-0.196(-1.42)$ & $-0.195(-1.40)$ & $-0.348(-3.21)$ \\
\hline cycle $_{t}$ & & 0.102 (1.19) & $0.102(1.18)$ & $0.156(1.41)$ \\
\hline & & $\boldsymbol{D E B T}_{t-1}>\tau^{D E B T}$ & $\boldsymbol{D E B T}_{t-1}>\tau_{t}^{D E B T}$ & cycle $_{t-1}>\tau^{\text {cycle }}$ \\
\hline$C V_{t-1}$ & & $-0.280(-2.54)$ & $-0.280(-2.54)$ & $-0.070(-0.48)$ \\
\hline cycle $_{t}$ & & $0.050(0.37)$ & $0.050(0.37)$ & 0.110 (1.11) \\
\hline$\tau^{D E B T}$ & & $69.1(4.32)$ & & \\
\hline$\gamma^{D E B T}$ & & $50.2(-)^{*}$ & $54.1(-)^{*}$ & \\
\hline$\tau^{\text {cycle }}$ & & & & 2.701 (2.94) \\
\hline$\gamma^{\text {cycle }}$ & & & & $29.2(-)^{*}$ \\
\hline$\tau_{0}^{D E B T}$ & & & $68.0(3.92)$ & \\
\hline$\tau_{1}^{D E B T}$ & & & $-3.80(-2.21)$ & \\
\hline Regression s.e. & 1.89 & 1.87 & 1.83 & 1.87 \\
\hline Adjusted $R^{2}$ & 0.13 & 0.14 & 0.20 & 0.14 \\
\hline Far (p-value) & 0.84 & 0.86 & 0.85 & 0.83 \\
\hline Farch (p-value) & 0.32 & 0.34 & 0.35 & 0.33 \\
\hline F-Chow ( $p$-value) & 0.00 & 0.11 & 0.15 & 0.10 \\
\hline
\end{tabular}

Notes: $t$-ratios in parentheses. * Imposed value. van Dijk et al. (2002) argue that the likelihood function is very insensitive to $\gamma$, suggesting that precise estimation of this parameter is unlikely. For this reason, we run a grid search in the range $[0.1,250]$ and fix the $\gamma$ parameter to the one that delivers the best fit of the estimated models. Far is the Lagrange Multiplier F-test for $2^{\text {nd }}$ order serial correlation. Farch is the $1^{\text {st }}$ order ARCH F-test. F-Chow is the Chow forecast F-test for structural stability (we test for a break in 2007). 
Table 2: IRELAND-OLS estimates of alternative models for $\triangle P R I M S U R P L_{t}, 1970-2012$

\begin{tabular}{|c|c|c|c|c|}
\hline & (i) Linear model & $\begin{array}{l}\text { (ii) Logistic model (2)- } \\
\text { (3) in text with } \\
s_{t-1}=D E B T_{t-1}\end{array}$ & $\begin{array}{l}\text { (iii) Logistic model (2)-(4) } \\
\text { in text with } s_{t-1}=D E B T_{t-1} \\
\text { and state-varying threshold }\end{array}$ & $\begin{array}{l}\text { (iv) Logistic model } \\
\text { (2)-(3) in text with } \\
s_{t-1}=\text { cycle }_{t-1}\end{array}$ \\
\hline Intercept & $-2.777(-1.66)$ & $-3.136(-1.81)$ & $-3.333(-1.89)$ & $-2.532(-1.52)$ \\
\hline$C V_{t-1}$ & $-0.421(-4.43)$ & & & \\
\hline finpressure $_{t}$ & $0.173(0.11)$ & $0.116(0.06)$ & $0.183(0.10)$ & $-0.214(-0.13)$ \\
\hline$\Delta D E B T_{t-1}$ & 0.161 (1.09) & 0.159 (1.07) & $0.153(1.05)$ & 0.148 (1.11) \\
\hline cycle $_{t}$ & 0.582 (3.11) & & & \\
\hline & & $\boldsymbol{D E B T}_{t-1}<\tau^{D E B T}$ & $\boldsymbol{D E B T}_{t-1}<\tau_{t}^{D E B T}$ & cycle $_{t-1}<\tau^{\text {cycle }}$ \\
\hline$C V_{t-1}$ & & $-0.210(-0.72)$ & $-0.170(-0.52)$ & $-0.450(-3.90)$ \\
\hline cycle $_{t}$ & & $0.585(1.80)$ & 0.587 (1.58) & $0.787(2.50)$ \\
\hline & & $\boldsymbol{D E B B}_{t-1}>\tau^{D E B T}$ & $\boldsymbol{D E B T}_{t-1}>\tau_{t}^{D E B T}$ & cycle $_{t-1}>\tau^{\text {cycle }}$ \\
\hline$C V_{t-1}$ & & $-0.484(-4.31)$ & $-0.491(-4.36)$ & $-0.250(-1.22)$ \\
\hline cycle $_{t}$ & & $0.603(2.90)$ & $0.628(3.77)$ & $0.474(2.27)$ \\
\hline$\tau^{D E B T}$ & & $49.0(4.24)$ & & \\
\hline$\gamma^{D E B T}$ & & $19.3(-)^{*}$ & $20.3(-)^{*}$ & \\
\hline$\tau^{\text {cycle }}$ & & & & $2.987(2.56)$ \\
\hline$\gamma^{\text {cycle }}$ & & & & $9.2(-)^{*}$ \\
\hline$\tau_{0}^{D E B T}$ & & & 48.0 (3.93) & \\
\hline$\tau_{1}^{D E B T}$ & & & $-4.01(-2.33)$ & \\
\hline Regression s.e. & 3.74 & 3.72 & 3.69 & 3.71 \\
\hline Adjusted $R^{2}$ & 0.35 & 0.37 & 0.38 & 0.37 \\
\hline Far ( $p$-value) & 0.12 & 0.14 & 0.18 & 0.19 \\
\hline Farch (p-value) & 0.33 & 0.34 & 0.34 & 0.35 \\
\hline F-Chow ( $p$-value) & 0.00 & 0.12 & 0.16 & 0.13 \\
\hline
\end{tabular}

Notes: See the notes of Table 1. 
Table 3: PORTUGAL-OLS estimates of alternative models for $\triangle P R I M S U R P L_{t}, 1960-2012$

\begin{tabular}{|c|c|c|c|c|}
\hline & (i) Linear model & $\begin{array}{l}\text { (ii) Logistic model (2)- } \\
\text { (3) in text with } \\
s_{t-1}=D E B T_{t-1}\end{array}$ & $\begin{array}{l}\text { (iii) Logistic model (2)-(4) } \\
\text { in text with } s_{t-1}=D E B T_{t-1} \\
\text { and state-varying threshold }\end{array}$ & $\begin{array}{l}\text { (iv) Logistic model } \\
\text { (2)-(3) in text with } \\
s_{t-1}=\text { cycle }_{t-1}\end{array}$ \\
\hline Intercept & $-1.016(-1.45)$ & $-1.128(-1.64)$ & $-1.129(-1.64)$ & $-1.080(-1.50)$ \\
\hline$C V_{t-1}$ & $-0.305(-2.42)$ & & & \\
\hline finpressure $_{t}$ & $0.027(0.04)$ & $-0.434(-0.54)$ & $-0.450(-0.56)$ & $-0.147(-0.21)$ \\
\hline$\triangle D E B T_{t-1}$ & 0.126 (1.35) & 0.170 (1.64) & 0.170 (1.65) & $0.082(0.85)$ \\
\hline \multirow[t]{2}{*}{ cycle $_{t}$} & 0.212 (2.19) & & & \\
\hline & & $\boldsymbol{D E B T}_{t-1}<\tau^{D E B T}$ & $\boldsymbol{D E B T}_{t-1}<\tau_{t}^{D E B T}$ & cycle $_{t-1}<\tau^{\text {cycle }}$ \\
\hline$C V_{t-1}$ & & $-0.142(-0.94)$ & $-0.140(-0.92)$ & $-0.493(-2.80)$ \\
\hline \multirow[t]{2}{*}{ cycle $_{t}$} & & 0.185 (1.97) & 0.185 (1.97) & 0.551 (2.75) \\
\hline & & $\boldsymbol{D E B T}_{t-1}>\tau^{D E B T}$ & $\boldsymbol{D E B T}_{t-1}>\tau_{t}^{D E B T}$ & cycle $_{t-1}>\tau^{\text {cycle }}$ \\
\hline$C V_{t-1}$ & & $-0.470(-2.75)$ & $-0.464(-2.76)$ & $-0.114(-0.73)$ \\
\hline cycle $_{t}$ & & $0.470(2.83)$ & $0.471(2.83)$ & 0.161 (1.69) \\
\hline$\tau^{D E B T}$ & & $47.0(3.24)$ & & \\
\hline$\gamma^{D E B T}$ & & $24.0(-)^{*}$ & $25.1(-)^{*}$ & \\
\hline$\tau^{\text {cycle }}$ & & & & $2.999(2.87)$ \\
\hline$\gamma^{\text {cycle }}$ & & & & $47.1(-)^{*}$ \\
\hline$\tau_{0}^{D E B T}$ & & & $45.2(2.99)$ & \\
\hline$\tau_{1}^{D E B T}$ & & & $-3.20(-2.34)$ & \\
\hline Regression s.e. & 1.81 & 1.70 & 1.68 & 1.71 \\
\hline Adjusted $R^{2}$ & 0.25 & 0.32 & 0.33 & 0.32 \\
\hline Far (p-value) & 0.19 & 0.20 & 0.20 & 0.20 \\
\hline Farch (p-value) & 0.78 & 0.77 & 0.77 & 0.78 \\
\hline F-Chow (p-value) & $0.00-$ & 0.13 & 0.15 & 0.13 \\
\hline
\end{tabular}


Table 4: SPAIN-OLS estimates of alternative models for $\triangle P R I M S U R P L_{t}, 1970-2012$

\begin{tabular}{|c|c|c|c|c|}
\hline & (i) Linear model & $\begin{array}{l}\text { (ii) Logistic model (2)-(3) } \\
\text { in text with } \\
s_{t-1}=D E B T_{t-1}\end{array}$ & $\begin{array}{l}\text { (iii) Logistic model (2)-(4) } \\
\text { in text with } s_{t-1}=D E B T_{t-1} \\
\text { and state-varying threshold }\end{array}$ & $\begin{array}{l}\text { (iv) Logistic model } \\
\text { (2)-(3) in text with } \\
s_{t-1}=\text { cycle }_{t-1}\end{array}$ \\
\hline Intercept & $-0.423(-0.69)$ & $-0.549(-0.89)$ & $-0.395(-0.66)$ & $-0.590(-0.91)$ \\
\hline$C V_{t-1}$ & $-0.284(-2.27)$ & & & \\
\hline finpressure $_{t}$ & $-1.180(-2.01)$ & $-1.177(-2.00)$ & $-1.372(-2.33)$ & $-1.153(-1.88)$ \\
\hline$\Delta D E B T_{t-1}$ & $0.087(1.10)$ & $0.070(0.83)$ & $0.072(0.89)$ & $0.064(0.71)$ \\
\hline cycle $_{t}$ & $0.438(4.06)$ & & & \\
\hline & & $\boldsymbol{D E B T}_{\boldsymbol{t - 1}}<\tau^{D E B T}$ & $\boldsymbol{D E B T}_{t-1}<\tau_{t}^{D E B T}$ & cycle $_{t-1}<\tau^{\text {cycle }}$ \\
\hline$C V_{t-1}$ & & $-0.245(-1.48)$ & $-0.178(-1.04)$ & $-0.340(-2.37)$ \\
\hline cycle $_{t}$ & & $0.384(3.41)$ & $0.334(2.83)$ & $0.584(3.08)$ \\
\hline & & $\boldsymbol{D E B T}_{t-1}>\tau^{D E B T}$ & $\boldsymbol{D E B T}_{t-1}>\tau_{t}^{D E B T}$ & cycle $_{t-1}>\tau^{\text {cycle }}$ \\
\hline$C V_{t-1}$ & & $-0.371(-2.54)$ & $-0.365(-2.64)$ & $-0.193(-0.87)$ \\
\hline cycle $_{t}$ & & 0.616 (3.95) & 0.596 (4.43) & 0.410 (3.64) \\
\hline$\tau^{D E B T}$ & & $43.0(3.24)$ & & \\
\hline$\gamma^{D E B T}$ & & $29.4(-)^{*}$ & $25.7(-)^{*}$ & \\
\hline$\tau^{\text {cycle }}$ & & & & $3.101(2.87)$ \\
\hline$\gamma^{\text {cycle }}$ & & & & $44.1(-)^{*}$ \\
\hline$\tau_{0}^{D E B T}$ & & & 44.1 (2.98) & \\
\hline$\tau_{1}^{D E B T}$ & & & $-2.50(-2.34)$ & \\
\hline Regression s.e. & 1.35 & 1.32 & 1.30 & 1.34 \\
\hline Adjusted $R^{2}$ & 0.49 & 0.53 & 0.54 & 0.51 \\
\hline Far (p-value) & 0.86 & 0.85 & 0.83 & 0.84 \\
\hline Farch (p-value) & 0.11 & 0.20 & 0.22 & 0.23 \\
\hline F-Chow (p-value) & 0.00 & 0.12 & 0.14 & 0.12 \\
\hline
\end{tabular}

Notes: See the notes of Table 1. 
Figure 1. Primary surplus and debt (\% OF GDP) for the GIPS
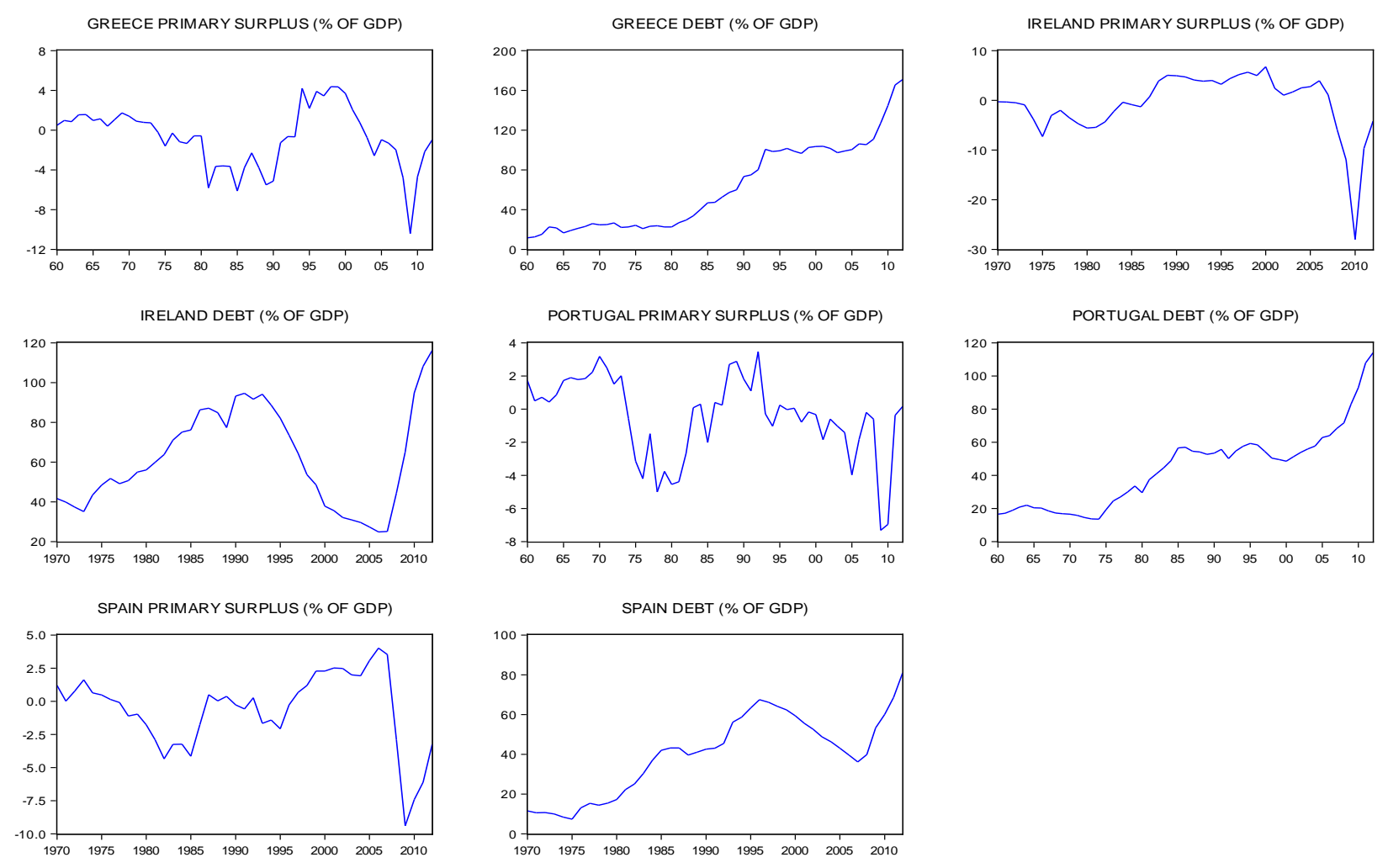

Figure 2. Output growth and financial pressure variable
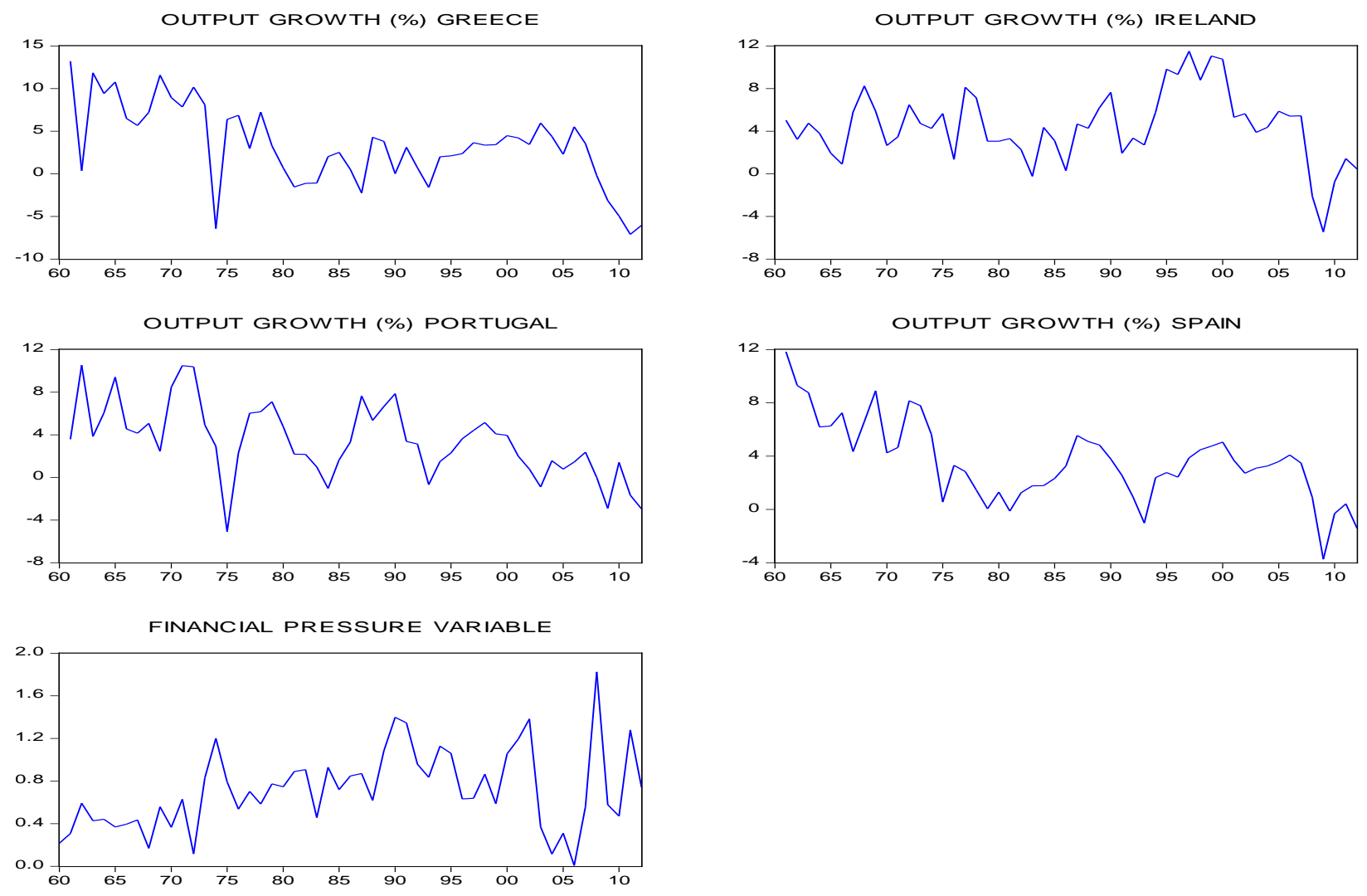